\title{
Perceptions of hospital admission in patients with cystic fibrosis
}

\author{
Merel Visse ${ }^{1}$, Tineke Abma ${ }^{1}$, Hetty van den Oever ${ }^{1}$, Yvonne Prins ${ }^{1}$, Vincent Gulmans ${ }^{2}$ \\ 1. VU University Medical Center, EMGO+ Institute for Health and Care Research, Department of Medical Humanities, \\ Amsterdam, The Netherlands. 2. Dutch Cystic Fibrosis Foundation (NCFS), Baarn, The Netherlands \\ Correspondence: Merel Visse. Address: Vu medical center, EMGO+ Institute for Health and Care Research, Department \\ Medical Humanities, Van der Boechorstraat 7, 1081 BT Amsterdam, The Netherlands. E-mail: m.visse@vumc.nl
}

Received: January 16, 2012

Accepted: February 20, 2012

Online Published: March 7, 2013

DOI : $10.5430 /$ jha.v2n3p54

URL: http://dx.doi.org/10.5430/jha.v2n3p54

\section{Abstract}

Aims and objectives: This paper is a report of a study of experiences of people with Cystic Fibrosis (CF) with their hospital admission. It evaluates how they perceive their treatment and care and the impact on their social life (school or work).

Background: In The Netherlands, people with CF are hospitalized in seven CF centers. In general, hospitalization may raise several challenges concerning the patient's psychosocial well-being, before, during and after the admission. The admission of people with CF is complicated, because of segregated treatment and care that aims to prevent hospital-based cross-infection.

Design: This article reports on a qualitative study.

Methods: Data were collected during 2009 and 2010. Nineteen people with CF admitted for more than 5 days in one of the seven Dutch CF-centres participated.

Results and conclusions: The findings are organized into five contexts with subthemes: Before admission \& Arrival (1); Treatment \& Care (2); Room \& Stay (3); Discharge (4); Social \& Societal context (5). The findings show that patients express a need for enhancing the quality of some treatments, like intravenous injections and patients express normative expectations of professionals that directly relate to their psychosocial well-being, e.g. they want to be 'seen' and treated as human beings and not solely as patients. They desire segregation policies to be consistent, whilst simultaneously they prefer flexible segregation guidelines. In general, respondents are satisfied with hospital facilities. The study reports on challenges concerning continuation of school and work during the admission. The paper is relevant to every hospital where people are being nursed in isolation.

\section{Key words}

Hospital admission, Psychosocial impact, Hospitalization, Segregation, Patient perspectives, Technical competence

\section{I ntroduction}

Cystic Fibrosis (CF) is a severe, inherited chronic disease. The incidence of CF varies. In the European Union 1 in 2,000-3,000 newborns is found to be affected by CF. In The Netherlands this concerns 1 in 4,750 newborns ${ }^{[1]}$. In the 
United States the incidence of CF is reported to be 1 in every 3,500 births ${ }^{[2]}$. In the Netherlands, where some 1,350 people live with CF, there are seven multidisciplinary Cystic Fibrosis centers (CF centers) responsible for the treatment and care of people with CF. Supervised by a pulmonologist or a paediatric pulmonologist, a team of specialized nurses, dieticians, physiotherapists, psychologists and social workers treat and care for people with CF.

The advances for diagnosis, treatment and care have improved considerably over the past few decades. Despite this, CF is still a complex disease with a wide variety of symptoms and severity, and an unpredictable course. The number of hospital admissions is expected to rise in the near future as people live longer and require hospitalized treatment. People with CF live longer due to advances in treatment, but the cost is that they require more frequent hospital admissions to manage exacerbations. Admissions to hospital can have a negative impact upon quality of life and psychosocial well-being. It interrupts a patient's private and social life. Hospitalizations of people with CF are even more complex because of in-hospital segregation measures which most countries, including the Netherlands, have introduced.

People with CF have a high rate of infection with Pseudomonas aeruginosa and this is why patients are segregated from from other patients with CF". Research demonstrates that cross infection may occur ${ }^{[3-5]}$. Therefore, in 2004, Dutch CF-centres introduced segregation policies with a view toward preventing cross infection. People are hospitalized in separate rooms and may leave the room ('outdoor period') only at set times of the day. The literature reports on the negative consequences of segregation for the quality of life and psychosocial functioning of people with $\mathrm{CF}^{[6-8]}$. Other factors may also influence patients' perceptions of their admission, including the quality of their relationships with nurses and clinicians and the opportunity to have a say in treatment and care. There is a growing interest in improving the quality of life for people with CF in the CF-centres ${ }^{[9]}$. However, to date little research has been published in this area ${ }^{[10]}$.

We conducted a qualitative study in order to understand how patients perceived these and other areas of their hospital admission. Clinical nurses and other clinical practitioners may benefit from the findings of this study to support people with CF during and after their hospital admission. The findings are relevant to every situation where people are being treated in isolation.

\section{Methods}

\subsection{Research approach}

This study was conducted in line with a qualitative research approach. The central aim of a qualitative study is to enhance understanding of complex practices ${ }^{[11]}$.

\subsection{Sampling procedure}

We strived for maximum-variation sampling: sampling as wide a range of perspectives as possible to capture the broadest set of information and experiences ${ }^{[12]}$. CF-specialized nurses at the seven CF centres were invited by letter to help recruit respondents for interview. We aimed to include four respondents from each CF centre (28 respondents in total, see criteria in Table 1).

The nurses recruited people before their admission. During the intake conversation by the nurse before the admission of a patient, she explained the purpose and procedure of the research to the patient. Simultaneously, the nurses handed over a written leaflet with procedural information (data collection, analysis and use of the diaries). Some specialized nurses informed us that recruiting respondents was challenging, as they had no time to recruit respondents because wards were understaffed. Next, at the start of the study, only a few potential participants met our criteria due to the relatively expected short admission duration. We therefore decided to change one selection criterion: admissions of 5 days or longer would be included, instead of admissions of 10 days or longer. When patients agreed to participate, the specialized nurse asked them 
to sign a confidentiality and informed consent form for all collected data (interviews and diaries). Respondents were included in the study between November 2009 and July 2010. The sample comprised 19 respondents.

Table 1. Criteria for inclusion in the study

Men and women with CF;

People with CF admitted to hospital because of a lung exacerbation;

whose length of hospital stay is expected to be between 10 days -6 weeks;

And who are in one of the following age groups:

Children with CF between 12 and 18;

Adults with CF in the $19-25$ age range, and 26 years or older.

This study understands 'hospital admission' to mean: the period prior to admission, actual admission, and aftercare. This study focuses on a minimum hospital stay of ten days (this was changed during the inclusion procedure to five days - see 'methods' section).

People admitted with intestinal problems were not included in the study.

\subsection{Literature search, interview guide and topic list}

A semi-structured interview guide was developed from an exploratory literature search of several international databases (e.g. PubMed, Chinal and Cochrane Library). The search strings we used consist of terms used to explore CF-patients' experiences with hospital admission, such as 'experiences patients' in conjunction with 'hospital admission' and 'segregation'. We also studied Dutch sources, both primary and secondary scientific and tertiary literature ${ }^{[13]}$. Empirical scientific studies with a method section are primary sources and other studies without a method section are secondary sources. Tertiary literature concerns nonscientific publications, reports and patient information that is relevant to our study. We then conducted a tentative interview. A draft topic list was developed. We also collected self-reported patient characteristics.

Figure 1. Overview of recruitment and instruction procedure

\begin{tabular}{|c|c|c|c|c|}
\hline \multicolumn{3}{|c|}{$\begin{array}{l}\text { Recruitment and instruction } \\
\text { within hospital setting by specialized nurses }\end{array}$} & & $\begin{array}{l}\text { Data collection in } \\
\text { research setting }\end{array}$ \\
\hline $\begin{array}{l}\text { Recruitment } \\
\text { during } \\
\text { admission by } \\
\text { specialized } \\
\text { nurses } \\
\text { according to } \\
\text { selection } \\
\text { criteria. }\end{array}$ & $\begin{array}{l}\text { If potential } \\
\text { participant is } \\
\text { interested: } \\
\text { inviting him to } \\
\text { keep a diary and } \\
\text { signing an } \\
\text { informed } \\
\text { consent form (by } \\
\text { specialized } \\
\text { nurses). }\end{array}$ & $\begin{array}{l}\text { Specialized } \\
\text { nurse } \\
\text { provides } \\
\text { respondent } \\
\text { with a diary } \\
\text { and guiding } \\
\text { instructions } \\
\text { to use the } \\
\text { diary. }\end{array}$ & \begin{tabular}{|c}
$\begin{array}{c}\text { Transfer of } \\
\text { participant } \\
\text { (contact) } \\
\text { information } \\
\text { from nurses to } \\
\text { researchers }\end{array}$ \\
Meanwhile \\
participants are \\
hospitalized \\
and 17 \\
participants \\
keep a diary
\end{tabular} & $\begin{array}{l}\text { In-depth semi- } \\
\text { structured } \\
\text { interview. } \\
\text { Participant } \\
\text { benefits from diary } \\
\text { during the } \\
\text { interview. After } \\
\text { the interview the } \\
\text { diary is handed } \\
\text { over to researcher } \\
\text { and participant } \\
\text { receives hard } \\
\text { copy. }\end{array}$ \\
\hline
\end{tabular}

\subsection{Data collection}

A total of 19 in-depth interviews were held around two weeks following discharge from hospital. The interviews were conducted by the first and third author separately and took between one and a half and two hours. During the interviews, the researcher asked questions related to the predefined topics and participants were invited to share topics that were not explicitly addressed by the researcher. To increase rigor as a method of triangulation, on admission, participants were given a notebook and asked to use it as a diary. They were informed about the purpose of the diary and that would be 
handed over to the researchers afterwards. The notebook contained a brief guide with questions (e.g. Can you write something about how you experienced your first admission day? How did you experience your contact with the nursing staff?) . The diary-instructions stressed that we were interested in experiences with the current admission. Participants were not obliged to use this notebook, and if they didn't they were still included in the project. In total, 17 respondents actually kept a diary. Two respondents did not - they did not have enough time, or they found the writing itself difficult.

During the interview participants benefited from their diary. The diary functioned as a personal 'reminder' of the admission experiences and this increases rigor. After the interview, the diary was handed over to the researcher (with consent). All interviews were digitally recorded after consent and transcribed verbatim by a research assistant. In order to check our interpretation of the interview, the respondents received a printout of our interpretation and asked whether they recognized it, or wanted to change or add anything (member check).

\subsection{Data analysis}

The transcripts and diaries were analysed thematically and simultaneously according to a content analysis approach, a technique for making replicable and valid inferences from texts to the contexts of their use ${ }^{[14]}$. The texts were divided into fragments, and fragment labels (codes) were assigned (open coding). Codes were then assigned to categories, and the categories from several transcripts were related (axial coding).

Table 2. Example of content analysis

\begin{tabular}{|c|c|c|c|}
\hline 1st level & 2nd level & 3rd level & 4th level \\
\hline Fragment transcript & open coding & category & axial coding \\
\hline $\begin{array}{l}\text { Just before I left for the hospital, I } \\
\text { heard that my neighbours' } \\
\text { eight-week-old baby was suffering }\end{array}$ & & & \\
\hline $\begin{array}{l}\text { from CF. We are very close to our } \\
\text { neighbours and this meant I couldn't } \\
\text { just go and visit my neighbours } \\
\text { anymore. That really hit me right } \\
\text { before I was admitted. I am pretty } \\
\text { down to earth, but that really got to } \\
\text { me. }\end{array}$ & $\begin{array}{l}\text { Hard time coping with news } \\
\text { of baby with CF. } \\
\text { Good contact neighbour. } \\
\text { Events before admission. }\end{array}$ & $\begin{array}{l}\text { Other people with CF } \\
\text { and limitations in } \\
\text { contact. }\end{array}$ & $\begin{array}{l}\text { Impact of segregation } \\
\text { Social contacts }\end{array}$ \\
\hline
\end{tabular}

\subsection{Quality procedures}

Internal validity is enhanced by conducting member checks with respondents and (reflexive) peer debriefing by the authors of this article ${ }^{[15,16]}$. The analysis was conducted by the first three authors. The role of the last two authors was to critically reflect on the interpretations of the first three authors. By combining several data collection methods (triangulation by interviews, diary, and literature search), the validity and reliability were enhanced; triangulation makes it possible to detect data in-congruencies. 'Thick descriptions' of the study context and meanings endowed to experiences enhance the transferability of the findings, i.e. the possibility of translating the themes to other socio-cultural contexts ${ }^{[17]}$.

\subsection{Ethical considerations}

We aimed for informed consent, anonymity, respect for privacy/confidentiality and transparency. It appeared that the project did not need to be submitted to an accredited Dutch Medical Research Ethics Committee (aMREC) for approval because the study did not concern medical research or any form of invasion of the study participant's integrity. We worked with informed consent forms, and participant names were not used in any of the research reports. 


\section{Results}

\subsection{Participants}

A total of 19 respondents with the following characteristics participated:

Table 3. Respondents characteristics $(\mathrm{n}=19)$

\begin{tabular}{|c|c|c|c|c|c|c|}
\hline Nr. Resp & Gender & Age & Situation at home & $\begin{array}{l}\text { Admission to adult / } \\
\text { children`s department }\end{array}$ & $\begin{array}{l}\text { Regular admission } \\
\text { involving I.V. } \\
\text { antibiotic cure }\end{array}$ & $\begin{array}{l}\text { Perception of condition : } \\
\text { 1. 'normal' } \\
\text { 2. 'controllable' } \\
\text { 3. 'distressing'" }\end{array}$ \\
\hline 1 & $\mathrm{M}$ & 40 & Living together & $\mathrm{A}$ & Yes & 3 \\
\hline $2 * *$ & $\mathrm{~F}$ & 17 & $\begin{array}{l}\text { Lives with } \\
\text { parents }\end{array}$ & $\mathrm{C}$ & Yes & 3 \\
\hline $3 * *$ & $\mathrm{~F}$ & 17 & $\begin{array}{l}\text { Lives with } \\
\text { parents }\end{array}$ & $\mathrm{C}$ & Yes & 2 \\
\hline 4 & $\mathrm{~F}$ & 39 & Married & A & Yes & 3 \\
\hline $5 * *$ & $\mathrm{~F}$ & 41 & $\begin{array}{l}\text { Lives with } \\
\text { parents }\end{array}$ & A & Yes & 3 \\
\hline 6 & $\mathrm{~F}$ & 31 & Single & $\mathrm{F}$ & Yes & 3 \\
\hline 7 & $\mathrm{~F}$ & 18 & $\begin{array}{l}\text { Lives with } \\
\text { parents }\end{array}$ & A & $\begin{array}{l}\text { No (last admission } \\
9 \text { months ago) }\end{array}$ & $2 / 3$ \\
\hline 8 & M & 14 & $\begin{array}{l}\text { Lives with } \\
\text { parents }\end{array}$ & $\mathrm{C}$ & Yes & 3 \\
\hline 9 & M & 29 & $\begin{array}{l}\text { Lives with } \\
\text { parents }\end{array}$ & A & Yes & 2 \\
\hline 10 & $\mathrm{~F}$ & 18 & $\begin{array}{l}\text { Lives with } \\
\text { parents }\end{array}$ & $\mathrm{C}$ & Yes & $2 / 3$ \\
\hline 11 & $\mathrm{~F}$ & 14 & $\begin{array}{l}\text { Lives with } \\
\text { parents }\end{array}$ & $\mathrm{C}$ & $\begin{array}{l}\text { No, 3d admission } \\
\text { to hospital }\end{array}$ & 3 \\
\hline 12 & $\mathrm{~F}$ & 50 & Married & A & Yes & 3 \\
\hline 13 & M & 37 & $\begin{array}{l}\text { Planning to live } \\
\text { together }\end{array}$ & A & Yes & 3 \\
\hline $14 * *$ & $\mathrm{~F}$ & 26 & Living together & A & No, 3d admission? & 2 \\
\hline 15 & $\mathrm{~F}$ & 33 & Single & A & Yes & 3 \\
\hline 16 & M & 50 & Married & A & Yes & 3 \\
\hline 17 & $\mathrm{~F}$ & 21 & $\begin{array}{l}\text { Lives with } \\
\text { parents }\end{array}$ & A & Yes & Recently transplanted \\
\hline 18 & M & 45 & $\begin{array}{l}\text { Married, with } \\
\text { children }\end{array}$ & A & Yes & 3 \\
\hline 19 & $\mathrm{~F}$ & 36 & $\begin{array}{l}\text { Widow, partner } \\
\text { passed away, } \\
\text { cause of death: } \\
\text { CF }\end{array}$ & A & $\begin{array}{l}\text { Partner was } \\
\text { admitted to } \\
\text { hospital several } \\
\text { times }\end{array}$ & \\
\hline
\end{tabular}

Re 1. 'normality' as not requiring hospitalisation for CF, or being in employment without needing any more sick leave than a 'healthy' person (p.297). Normality also included having an active social life.

Re 2. Respondents have an attitude of 'controlling' their health and this requires a considerable effort. Generally speaking, starting intravenous (IV) antibiotics marked a change from the perception of 'normal' health to one of health as a controllable state (p. 301).

Re 3 'health as distressing' involves daily disruption to work, social relations and hopes for the future as a result of the effects of emerging chronic illness (p. 306). Respondents are concerned about their health. IV is no longer as effective as it used to be, other solutions are sought (e.g. port-a-cath or PICC-line). People consider the transplant option.

** Respondents 2 and 3 were interviewed in the presence of their parents. Respondents 5 and 14 were interviewed in the presence of their spouses. 
Table 4. Respondents Information

\begin{tabular}{|c|c|c|c|c|c|c|c|c|c|c|c|}
\hline \multirow{2}{*}{$\begin{array}{l}\text { Number of } \\
\text { Respondents }\end{array}$} & \multicolumn{2}{|c|}{ Gender } & \multicolumn{3}{|l|}{ Age } & \multicolumn{2}{|c|}{ Regular admissions } & \multicolumn{4}{|c|}{ Perception of health } \\
\hline & $\mathbf{M}$ & $\mathbf{F}$ & $\leq 18$ & 19-40 & $\geq 41$ & Yes & No & 1 & 2 & 3 & N/A \\
\hline 19 & 6 & 13 & 6 & 9 & 4 & 16 & 3 & 0 & 5 & 12 & 2 \\
\hline $100 \%$ & $32 \%$ & $68 \%$ & $32 \%$ & $47 \%$ & $21 \%$ & $84 \%$ & $16 \%$ & 0 & $26 \%$ & $63 \%$ & $11 \%$ \\
\hline
\end{tabular}

Most respondents have been admitted to hospital several times in the past (84\%). This made it possible for them to compare different admissions (and may enhance the quality of the data). More women than men are represented

Most respondents were admitted on a regular basis (16 out of 19 respondents). Respondents of all seven CF centres are included. There are more females than males. A possible explanation for this may be the challenges we have met when including respondents as mentioned in the 'sampling' section.

\subsection{Contexts with themes}

The following five contexts with themes were identified:

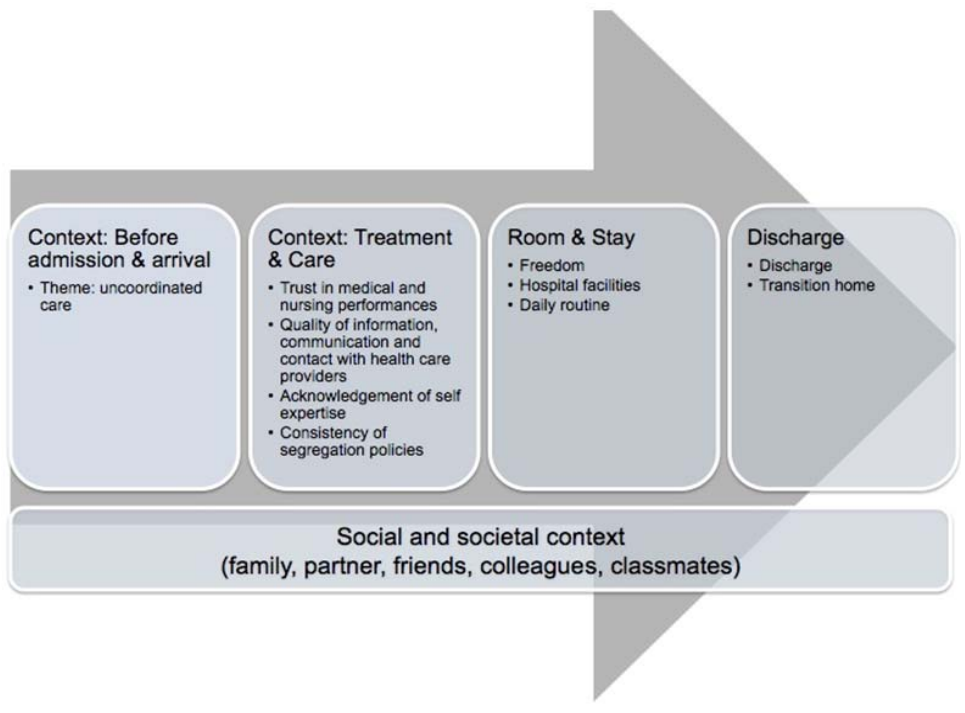

Figure 2. Context and their themes

We now describe the context and themes that emerged. Table 3 illustrates each context with one or more relevant quotes.

\subsubsection{Themes related to the time before admission and arrival on the ward}

The main theme in this context concerns: uncoordinated care. Respondents are not satisfied with their first day of admission. After arriving on the ward, they have to wait a considerable amount of time before starting treatment. Most respondents said they had to wait about six hours. They find this annoying (quote 1, Table 5); it makes them tired, and may also put a strain on patients who are accompanying them.

Apart from emergency situations, patients do not understand why they are sometimes admitted on a Friday, just before the weekend. Antibiotic treatment does continue over the weekend in Dutch hospitals, but apart from that, additional treatment e.g. physical therapy, is seldom provided. 


\subsubsection{Themes related to treatment and care}

Four themes found in the context of Treatment and Care, concern: (1) trust in technical performances by staff (2) quality of information, communication and contact (3) acknowledgement of self-expertise and (4) consistency of segregation policies.

Table 3. Themes and illustrative quotes

\begin{tabular}{|c|c|c|}
\hline $\begin{array}{l}\text { Quote no } \\
\text { (respondent) }\end{array}$ & Context & Respondent quote \\
\hline $\begin{array}{l}1 \\
(10)\end{array}$ & $\begin{array}{l}\text { Before admission \& } \\
\text { arrival }\end{array}$ & $\begin{array}{l}\text { I get there around eleven in the morning, but only get my antibiotics at seven in the } \\
\text { evening. I get someone to come with me, and my Dad takes time off, but it's a real pain } \\
\text { when the doctor doesn't come until late. }\end{array}$ \\
\hline $\begin{array}{l}2 \\
(5)\end{array}$ & & $\begin{array}{l}\text { In the middle of the night, half past five, or six, it was still dark (...) I felt I had to } \\
\text { watch: 'Are they doing this the right way? }\end{array}$ \\
\hline 3 & & $\begin{array}{l}\text { Yes, I.... and then I get my antibiotics, and think to myself: “Here I am on a drip, but } \\
\text { what else am I doing here?” I don't see anyone else at all. I'm all on my own.... yeh... }\end{array}$ \\
\hline (7) & & $\begin{array}{l}\text { (...). A nurse comes along every now and again to look at the drip, and then she's gone } \\
\text { again. And I'm just lying there...... }\end{array}$ \\
\hline $\begin{array}{l}4 \\
(13)\end{array}$ & & $\begin{array}{l}\text { If you've got CF then you've really got to keep an eye on yourself and see whether } \\
\text { things are OK or not. Because of course when they examine you they can see all sorts } \\
\text { of things, but not everything, so you've really got to say how you're feeling, and I said } \\
\text { I wasn't happy with things, and also because I'd been treated several times but it had } \\
\text { never really worked. }\end{array}$ \\
\hline $\begin{array}{l}5 \\
(13)\end{array}$ & & $\begin{array}{l}\text { I'm pretty sure my old doctor would have said: 'Prevention'...And also because that's } \\
\text { what I'd said..... There comes a time after a while when you know your body so well. } \\
\text { (...) and I think they didn't really have a good idea of what was going on... }\end{array}$ \\
\hline $\begin{array}{l}6 \\
(2)\end{array}$ & Treatment \& Care & $\begin{array}{l}\text { I really don't understand why we have to do a lung test so early. It's not right in the } \\
\text { morning, it gives the wrong idea. A bit of a waste of money. But they don't do anything } \\
\text { else, there's no time. I did tell them once, but you know what it's like.... }\end{array}$ \\
\hline $\begin{array}{l}7 \\
(12)\end{array}$ & & $\begin{array}{l}\text { I sometimes do it myself, and they say (...) “come on, you can do it, even when it’s } \\
\text { finished' [the nurses].” "Yes, that's right.” And then they [trainees] see what I'm doing } \\
\text {... and they come over to me and say "You really shouldn't be doing that yourself.” } \\
\text { "No, but I'm allowed to (do) it myself; go and ask the nurses.... they know I do it } \\
\text { myself.” }\end{array}$ \\
\hline $\begin{array}{l}8 \\
(9)\end{array}$ & & $\begin{array}{l}\text { There is a segregation policy, but they do tend to turn a blind eye a bit. It all depends } \\
\text { who is here with CF. It's really up to the adult CF patients themselves, and there are } \\
\text { people who couldn't care less and then the nurses should really say, 'we do have rules } \\
\text { for that kind of thing you know.' }\end{array}$ \\
\hline $\begin{array}{l}9 \\
(4)\end{array}$ & & $\begin{array}{l}\text { The segregation policy really isn't up too much. There you are all shut away and that's } \\
\text { not good for you... you have to get better but you can’t do anything apart from walk } \\
\text { from the bed to the door and back again. (...) We used to go and stretch our legs and } \\
\text { walk quite a way, but we can't do that anymore. It doesn't particularly help you get } \\
\text { better. }\end{array}$ \\
\hline $\begin{array}{l}10 \\
(14)\end{array}$ & Room \& Stay & $\begin{array}{l}\text { Meals were fine; there they come with a trolley in the morning and afternoon. Of } \\
\text { course the food's much better at home, but it really wasn't too bad at all. }\end{array}$ \\
\hline 11 & & You suddenly get really pissed off. My girlfriend and me. Yes, that's what happens. All \\
\hline (1) & Social \& societal & people with CF do that. About anything, is pure frustration. \\
\hline $\begin{array}{l}12 \\
(3)\end{array}$ & context & $\begin{array}{l}\text { It's really difficult to concentrate, because there are things happening all the time. I } \\
\text { once put up a sign saying 'I'm busy'. }\end{array}$ \\
\hline $\begin{array}{l}13 \\
(14)\end{array}$ & Discharge & $\begin{array}{l}\text { Only when I left I didn't see any of the nursing staff to say goodbye to, that's a bit } \\
\text { weird. And when I got home I realised I'd still got my wristband on. }\end{array}$ \\
\hline
\end{tabular}


Firstly, respondents have experienced situations where they have been given intravenous antibiotics that they have a sensitivity towards (e.g. in the case of allergies). Respondents experience this to be a medical error, because their files contain information on their medication sensitivity. They concluded that professionals didn't inform themselves thoroughly. This causes distress, even at night when some respondents watch the antibiotic drip very carefully (quote 2, Table 5). Patients experience pain when their veins are frequently punctured. They believe this pain could be avoided if someone with more experience were to do it (e.g. an anesthesiologist). They often ask whether an anesthesiologist can insert the intravenous line, but they often feel that no-one really listens to them. The respondents who have been given a venous access device, such as a Port-a-Cath or PICC line, were positive about their device and the provision of antibiotics by professionals.

Secondly, patients have several criteria for evaluating meetings with clinicians, nurses and other health-care professionals. The level of equality they experience in the relationship and the amount and nature of the attention they experience, is important. Respondents also value the accuracy and personal relevance of the information they are given, and the way practitioners communicate with them. Our findings demonstrate that this is not always the case. Above all, patients value human contact. Most respondents explicitly mention their desire to be seen as a unique human being, instead of as a case. Patients experience this notion of humanity in situations where there is humor and friendliness, for example. Despite the fact that nurses and physicians are relatively easy to contact, patients with CF believe that the quality of the contact needs to be improved. This relates to the quality of information and also the quality of 'attention' that professionals give (quote 3 , Table 5). Segregation has consequences for social contact and etiquette, such as handshaking. Both adults and children feel stigmatized if professionals do not introduce themselves according to social norms. They feel the need to be treated in the same way as other patients, and this includes shaking hands.

A third theme concerns the acknowledgement of self-expertise. Many patients with CF have become experts when it comes to their body and health. They also have clear opinions about what they need from a medical and technical perspective. They would like to see their experiential knowledge acknowledged. The majority of adult respondents seem to believe they themselves are partly responsible for their treatment and care (quote 4, Table 5). For example, one male respondent had surgery for a pneumothorax and had to recover in intensive care. He asked to be treated with preventive antibiotics, but his physician did not agree (quote 5, Table 5). The fact that patients need to have a say in treatment and care also applies to technical procedures, e.g. measuring lung function. Patients prefer their lung function to be measured in two different ways: with and without bronchodilators. (It is usually the case that only bronchodilators are used.) Several respondents stress the importance of timing; they believe measuring the lung function in the morning does not give the right reading because they need time to 'wake up' and so the results are biased (quote 6, Table 5). Despite these remarks, there have been no policy changes. One respondent negotiated certain privileges for her medical care with the nursing staff, but trainee nurses do not always accept this (e.g. quote 7, Table 5).

Lastly, a theme in the context of Treatment and Care concerns 'consistency of segregation policies'. Most young respondents ( $<18$ years) see segregation policies as acceptable. However, adult patients report inconsistencies surrounding segregation policies at the centres, and on how segregation was put into practice on the wards (quote 8 , Table 5). These inconsistencies are confusing, and they would like to see clarity on this matter. Respondents believe that some CF centres take a flexible stance: patients with CF should be able to decide for themselves whether or not to follow segregation guidelines. For most adult patients the negative consequences of segregation outweigh the positive effects. They believe that the chance of being infected by another patient is relatively slight. Only a handful of patients are genuinely concerned about cross-infection.

\subsubsection{Themes related to the context room and stay}

An important theme related to room and stay concerns 'freedom'. Most patients feel locked up and their freedom restricted. They believe segregation has a negative impact on their recovery because they can't be mobile or be in contact with other patients (quote 9, Table 5). The time set aside to leave their rooms is not acceptable. Respondents are 
disappointed when at the last moment they learn they are unable to go outside because a fellow patient just left his or her room.

Respondents reported on their experiences with the availability of rooms, room facilities, including facilities for visitors, design and atmosphere of the room, meals and hygiene. Generally, they are satisfied with these aspects of their room and stay. They appreciate the digital facilities available, such as a laptop and wireless internet. This enables them to be connected to patients in the outside world. Patients are also positive about the menus, but would like to decide themselves when their meal is served (quote 10, Table 5).

\subsubsection{Themes related to social context and participation in society}

Themes related to this context, concern: (1) flexible visiting hours (2) integration of school and work.

Respondents are satisfied with flexible visiting hours. They generally experience considerable support from their families and friends. Some respondents report that their intimate relationships undergo a few difficulties (quote 11, Table 5).

Young patients need more time do to their homework for school. According to them, the daily schedules when in hospital do not really take sufficient account of that (quote 12, Table 5).

Most adults have a part-time job and experience support from their colleagues. However, a few patients find returning to work a challenge and have to catch up without any extra support.

\subsubsection{Themes related to discharge}

Respondents are satisfied with the procedural aspects of their discharge. However, they would like to be able to say goodbye to nurses and other staff when they are discharged (quote 13, Table 5).

Treatment will often be continued at home, and the hospital pharmacy often prepares medication for this. However, some patients have to wait up to eight hours before they can get their medication.

\section{Discussion}

The findings raise four main subjects of discussion. The patients in the study articulate:

a) a need to have more control and better communication concerning their treatment and care; 2) a need to share decisions about segregation;

b) that they appreciate the quality of instrumental and technical skills;

c) that they experience challenges posed by social obligations, such as work and school.

This study has shown that patients with CF wish to have more control in their treatment and care. A small number of respondents $(n=3)$ actually felt they were in control of their treatment and care in the relationship with the care providers. The need for control is all the stronger because of the erratic way in which CF develops. Patients with CF, together with care providers to some extent, identify the priorities for their particular situation. They develop not only the patient's experiential, empirical knowledge, but often also intensive and long-term relationships with professionals. Patient compliance acquires a different meaning in this context, compared with the extent to which patients with CF 'obey' instructions on treatment and care, or follow segregation guidelines. Compliance is therefore determined in dialogue. Following Meichenbaum's \& Turk's ${ }^{[18]}$ example, we use the term 'adherence' or dialogic compliance: an active and voluntary involvement of the patient based on collaboration, in which the patient and the professional work jointly towards a desired outcome (adherence). In the context of this study, this means that decisions are made jointly and responsibilities are allotted through processes of shared decision making at various times during admission, such as the intake interview as 
conducted by nurses ${ }^{[19,20]}$. Linked to this process of shared decision making, patients articulate specific normative expectations. These expectations inform us about what the patient expects that should be done by whom and how. For example, respondents report their wish for these relationships to accommodate their 'humanity', their 'entire' story, and the 'person behind the patient'. These findings are in line with earlier studies of patients with CF and guidelines for care ${ }^{[21]}$.

The need to 'have a say' in treatment and care also applies to segregation policies. This study demonstrated that adult respondents were dissatisfied with the segregation policy, and felt that the disadvantages (limited freedom and human contact) outweighed the benefits (preventing infection). Their experience can be attributed to inconsistent enforcement, conflicting information about the risks involved, and patients' wish to retain control over their own lives. From a patient's perspective, more clarity on the risks is required. A formal patient education program regarding the transmission of infectious agents is suggested. Studies on shared decision making confirm the need for clear information, or, where there is a lack of information, the willingness of nurses and clinicians to address uncertainties ${ }^{[22]}$.

A third subject for discussion is the finding that patients with CF do not always have confidence in the technical expertise of care providers, such as nursing staff, junior physicians or ward doctors. This is particularly true when it comes to inserting an intravenous line, or changing antibiotic drips. According to patients, professionals such as nurses should be proficient in a range of skills, including technical competences. Other research confirms this: according to a literature review conducted by Rchaidia et al., 'knowledgeable and skillful nurses were seen as those having great experiential knowledge and technical competence' ${ }^{[23]}$. Their systematic review demonstrated that good nurses were aware of their professional limitations: they would know when to call in a doctor or a psychologist to offer psychosocial support. According to patients with CF, this is not always the case.

The findings show that experience with work and school is diverse. Whereas one respondent enjoys considerable support from colleagues, another is obliged to make up for lost time on return to work. Further research is desirable in order to increase our understanding of this subject. Other studies have shown that patients with CF have a variety of problems in striking a balance between care and work ${ }^{[24]}$. Few studies focus on how patients view hospital admission and work. Almost all the young patients with CF in this study had problems keeping up with their homework. Even though all CF Centres have special facilities for school, children with CF in our study could not find enough time or freedom from distraction to keep up with their schoolwork. Relatively little research has been carried out into the impact of admission on school and school performance. Further research is warranted.

There were several limitations to the study. A small amount of respondents were admitted to different CF centres in the past and this may have influenced the findings. Comparison of admission over lifetime and between centres may have positive and negative effects. It may have provided the evaluations of participants with more depth and nuance; yet, we do need to reckon with projection of former experiences on the current admission. Next, the study consisted of a relatively small sample of respondents. Despite this, the study gives a clear idea of the major themes that patients with CF face during their hospital admission. As demonstrated, the themes complement and enrich former studies. We would recommend a supplementary quantitative study in order to shed light on what the findings from this study mean for relatively large groups of patients with CF. The findings of this study could serve as input for developing a survey or questionnaire.

\section{Relevance to clinical practice}

We conclude with the relevance for the clinical practice. Clinical practitioners have an important responsibility in communicating of cross infection procedures. This should be part of routine standard care. In addition, clinical doctors and nurses could be advocates of themes like shared responsibility for segregated care. In order to invite patients to help decide about segregation, clinical doctors and nurses need to have the necessary communication skills to address uncertainties, explore and set expectations. This implies that a sufficient amount of time should be given to consultation and the 
exploration of what segregated care means for a patient and the impact of it for one's well-being. Furthermore, this relates to the wish of respondents for relationships that accommodate their 'humanity' ${ }^{[25]}$. Clinical practitioners could safeguard the basic needs of patients in order to provide care from basic values like listening, being responsive and sharing responsibilities ${ }^{[25,26]}$.

\section{References}

[1] Slieker, M.G., Uiterwaal, C.S.P.M., Sinaasappel, M., Heijerman, H.G.M., Laag, J. van der, Ent, C.K. van der. Birth prevalence and survival in cystic fibrosis: a national cohort study in the Netherlands. Chest. 2005; 128: 2309-15. PMid:16236889 http://dx.doi.org/10.1378/chest.128.4.2309

[2] World Health Organization. 2011.

[3] Festini, F., Buzzetti, R., Bassi, C., Braggion, C., Salvatore, D., Taccetti, G., Mastella, G. Isolation measures for prevention of infection with respiratory pathogens in Cystic Fibrosis: a systematic review. Journal of Hospital Infection. 2006; 64(1): 1-6. PMid:16835001 http://dx.doi.org/10.1016/j.jhin.2006.02.021

[4] Griffiths A.L., Armstrong D., Carzino R., Robinson P. Cystic Fibrosis patients and families support cross-infection measures. Eur Resp J. 2004; 24: 449-452. PMid:15358705 http://dx.doi.org/10.1183/09031936.04.00066803

[5] Speert D.P., Campbell M.E., Henry D.A., Milner R., Taha F., Gravelle A., Davidson A.G.F., Wong L.T.K., Mahenthiralingam E. Epidemiology of Pseudomonas aeruginosa in Cystic Fibrosis in British Columbia, Canada. American Journal of Respiratory and Critical Care Medicine. 2002; 166: 988-993. PMid:12359659 http://dx.doi.org/10.1164/rccm.2203011

[6] Russo K., Donnelly M., Reid A.J.M. Segregation-the perspectives of young patients and their parents. Journal of Cystic Fibrosis. 2006; 5: 93-99. PMid:16448864 http://dx.doi.org/10.1016/j.jcf.2005.12.002

[7] Duff A.J.A. Psychological consequences of segregation resulting from chronic Burkholderia cepacia infection in adults with CF. Thorax. 2002; 57: 756-758. PMCid:1746417 http://dx.doi.org/10.1136/thorax.57.9.756

[8] Griffiths A.L., Armstrong D., Carzino R., Robinson P. Cystic Fibrosis patients and families support cross-infection measures. Eur Resp J. 2004; 24: 449-452. PMid:15358705 http://dx.doi.org/10.1183/09031936.04.00066803

[9] Stern M., Niemann N., Wiedemann B., Wenzlaff P. Benchmarking improves quality in cystic fibrosis care: a pilot project in 12 centres. International Journal for Quality in Health Care. 2011; 23(3): 349-356. PMid:21504960 http://dx.doi.org/10.1093/intqhc/mzr017

[10] Russo K., Donnelly M., Reid A.J.M. Segregation-the perspectives of young patients and their parents. Journal of Cystic Fibrosis. 2006; 5: 93-99. PMid:16448864 http://dx.doi.org/10.1016/j.jcf.2005.12.002

[11] Freeman M. Validity in dialogic encounters with hermeneutic truth. Qualitative Inquiry. 2011; 17(6): 543-551. http://dx.doi.org/10.1177/1077800411409887

[12] Kuper A., Lingard L., Levinson W. Qualitative research; critically appraising qualitative research. British Medical Journal. 2008; 337: 687-689. http://dx.doi.org/10.1136/bmj.a1035

[13] For example, Boerhof, E.A. (2007) Invloed van het segregatiebeleid op het dagelijks functioneren van volwassen Cystic Fibrosis patienten, doctoraal scriptie (niet gepubliceerd) and Prins, Y. (2010) Langer zullen ze leven! Jubileumboek ter gelegenheid van 40 jaar NCFS. Uitgave: NCFS.

[14] Krippendorff, K. (2004) Content Analysis: An Introduction to Its Methodology (2nd ed.). Thousand Oaks, CA: Sage.

[15] Mays N., Pope C., eds. Qualitative research in health care. London: BMJ Publishing Group. 1996.

[16] Reeves, S., Albert, M., Kuper, A., \& Hodges, B. D. Why use theories in qualitative research? British Medical Journal. 2008; 337: 949. http://dx.doi.org/10.1136/bmj.a949

[17] Kuper A., Lingard L., Levinson W. Qualitative research; critically appraising qualitative research. British Medical Journal. 2008; 337: 687-689. http://dx.doi.org/10.1136/bmj.a1035

[18] Meichenbaum D., Turk D.C. Treatment adherence: terminology, incidence and conceptualization. In: Facilitating treatment adherence. New York: Plenum Press. 1987; 19-39. http://dx.doi.org/10.1007/978-1-4684-5359-1_2

[19] Elwyn G., Laitner S., Coulter A., Walker E., Watson P., Thompson R. Implementing shared decision making in the NHS. British Medical Journal. 2012; 341: c5146. http://dx.doi.org/10.1136/bmj.c5146

[20] Abma, T.A, B. Oeseburg, M. Goldsteen, G.A.M. Widdershoven and M. Verkerk. Two women with Multiple Sclerosis. Conflicting normative expectations between patients and their caregivers, Nursing Ethics. 2005; 12(5): 479-492. PMid:16178344 http://dx.doi.org/10.1191/0969733005ne816oa 
[21] Walters S. Doctor-patient relationship in Cystic Fibrosis—a patient's perspective. Holistic Medicine. 1990; 6: 157-162 and Kerem E., Conway S., Elborn S., Heijerman H. Standards of care for patients with Cystic Fibrosis: a European consensus. For the consensus committee. Journal of Cystic Fibrosis. 2005; 4: 7-26.

[22] Elwyn G., Edwards A., Gwyn R., Grol R. Towards a feasible model for shared decision making: focus group study with general practice registrars. British Medical Journal. 1999; 319: 753-756. PMid:10488002 http://dx.doi.org/10.1136/bmj.319.7212.753

[23] Rchaidia, L., Dierckx de Casterlé, B., De Blaeser, L., Gastmans, C. Cancer Patients’ Perceptions of the Good Nurse: a literature review. Nursing Ethics. 2009; 16(5): 528-542. PMid:19671641 http://dx.doi.org/10.1177/0969733009106647

[24] Demars N., Uluer A., Spencer T., Sawicki G. Perceptions of Employment among Adolescents and Young Adults with Cystic Fibrosis. Am J Respir Crit Care Med. 2009; 179: A1448.

[25] Visse, M.A. (2012) Openings for humanization in modern health care practices. PhDthesis, Vu Amsterdam

[26] Teunissen, G.J., M.A.Visse, W.I. de Boer, T. A. Abma (2011) Patient issues in health research and quality of care: an inventory and data synthesis. Health Expectations. Accepted. PMid:21771226 http://dx.doi.org/10.1111/j.1369-7625.2011.00718.x 